\title{
FRENCH LEARNERS OF L2 ENGLISH: INTONATION BOUNDARIES AND THE MARKING OF LEXICAL STRESS
}

\section{CELINE HoRGUES}

Université Sorbonne Nouvelle- Paris 3

celine.horgues@univ-paris3.fr

\begin{abstract}
In English, prosodic parameters play a major role at two main levels. First, they indicate the intonation at the level of the utterance by marking the distinction between sentence types (statements vs questions) and they are related - although more or less directly- to the informational and grammatical structures of the utterance. Secondly, prosodic cues also contribute to marking the stress pattern at the level of the word (word stress or lexical stress).

Even if it is useful to dissociate these two levels theoretically, when looking at their phonetic implementation in an utterance, it soon appears that the exact same prosodic cues are used (namely fundamental frequency, duration, and intensity). Contrary to what happens in tone languages, there is no pre-set prosodic configuration attached to each word in English. Yet, words in discourse retain a relative accentual independence even though the exact prosodic implementation of word stress depends on the specific intonational context expressed in a given utterance (Pierrehumbert, 1980).

In French, stress pertains to the level of the group of words rather than to the individual word, which has no real accentual autonomy. Therefore, it is not surprising that French learners of English are faced with a major challenge: how to ensure the marking of lexical stress while, at the same time, using the same prosodic cues to indicate the intonational structure of the utterance.

My hypothesis is that some intonational contexts impose a bigger constraint on French learners of English than others. These particularly challenging contexts are the final position at the boundary of non-final clause, or the boundary of a rising interrogative. Other contexts, like the quotation form or the final position of a statement, are less challenging for the intonational marking of lexical stress.

To test my hypothesis, I collected passages of read speech by thirteen upper intermediate/advanced French learners of English along with the same passage read by ten native English speakers. Two trisyllabics carrying primary stress on the second syllable (com'puter, pro'tection) were placed in a series of intonational contexts under observation. The test-words were then extracted and submitted to native English listeners. The perceptual results show that the predicted 'challenging' contexts indeed caused substantial instability in the learners' placement of lexical stress as perceived by native English listeners.
\end{abstract}

Keywords: French-accented English, prosody, word stress, intonational boundaries. 


\section{Introduction}

When looking into the acquisition of prosody, researchers and teachers are faced with an intriguing paradox: prosody is one of the first language features to be acquired in one's mother tongue (Konopczynski, 1991, Dupoux et al., 2003) and its acquisition possibly starts even before birth (Kuhl and Iverson, 1995), but when later learning a second language (henceforth L2), prosody remains a challenge even at the later stages of L2 learning (Tahta et al., 1981 and Hewings, 1998 ${ }^{1}$ ).

French learners of L2 English are known for being easily identified (mainly but not exclusively) through the prosodic specificities of their interlanguage, which make them perceptively distinct from native English speakers. A previous perception experiment based on low-pass filtered speech showed that when native English listeners were asked to listen to the same sentence read by native speakers and by French learners of L2 English $^{2}$, prosody alone was a sufficient cue for their identification of French accent in English (Horgues, 2010).

One of the questions at stake is the origin of the observed prosodic deviations from L2 norms: Do they result from the prosodic interference from the L1 (in our case L1French)? Or are they influenced by other external factors which are not specific to the L1?

I use the term 'prosody' in its broadest sense: encompassing the phenomena of word stress and sentence stress, rhythm, intonation, and related phenomena like pauses and segmental cues attached to stressed $v s$ unstressed syllables [see Vaissière, 2002].

Among the prosodic characteristics of French-accented English, the perception and production of English word stress has long been an acknowledged difficulty for French learners. Some psycholinguists have even referred to it as a case of 'stress-deafness' (Dupoux and Peperkamp, 2002). But it is now worth looking at the question of the realisation of English word stress by French learners - not as an isolated phenomenon but in its interaction with other prosodic levels in an utterance: especially the intonational level in the utterance, which I call the supra-lexical level, i.e. above the level of the individual word. It is interesting to observe how the phonetic realisations of these two levels (both lexical and supra-lexical) are closely intertwined.

My hypothesis is that some intonational contexts are more challenging than others for the prosodic marking of word stress by French learners. L1 prosody (French prosody) being largely (but not solely) responsible for these difficulties, I will start by giving a comparative overview of the prosodic features of L1-French and L1-English relevant to the present study. I will subsequently expand on what I mean by challenging contexts, before presenting the experimental setup I devised to test my hypothesis. The experimental results I collected will finally point to possible pedagogical implications.

\footnotetext{
${ }^{1}$ Hewings (1998: 318) : "Intonation features of a foreign accent are the last and perhaps the most difficult to eradicate (the prosodic system of a language is the last to be mastered, it tends to become fossilised in advanced learners and it remains to characterise learners as having a foreign accent after segmental deviations from the target language have been eradicated)."

2 Even when based on a relatively short sentence like: "Henry looked at him rather unpleasantly". Some distractors (the same sentence read by a German and an Italian learner) were also presented to the listeners.
} 


\section{Comparing some prosodic features of L1-French and L1-English}

Prosodic analysis is a complex area due to the fact that the same basic acoustic cues (mainly the fundamental frequency, the duration, and the intensity, and sometimes vowel quality) implement the form of different linguistic levels. Indeed, not only do they ensure the marking of intonation at the level of the utterance (syntactic and informational structures) but they are also used to indicate word stress. However, the relation between sentence intonation and word stress is not the same in French and in English.

\subsection{French: word stress and intonational boundaries}

Following, Troutbetzkoy (1939) and Garde (1968), the traditional opposition between so-called 'free-stress' or 'mobile stress' languages (like English) and so-called 'fixedstress' languages (like French) is in fact misleading.

In particular it is difficult to say that word stress is fixed in French since stress does not systematically affect the last syllable of words. Incidentally, perception experiments have shown that French listeners obtain a low rate of agreement when asked to identify the placement of word stress in their mother tongue and word stress in French has been described as more "fleeting" (fuyant) than in other romance languages (Fónagy, 1980). Phoneticians thus now prefer to speak about group accent rather than word stress when describing French (Vaissière, 2002 and Martin, 2009). They generally agree that stress in French belongs to the level of the group of words as opposed to the individual word, which has no real accentual autonomy. Accent is associated with the rhythmic group boundaries: the last syllable in a prosodic unit is stressed. It functions as a demarcation accent indicating the final boundary and it is sometimes supplemented by an optional initial accent to mark the start of the unit, therefore creating an accentual bridge between the group-initial and the group final accent. The acoustic correlates of the final demarcation accent in French are a clear lengthening of the final syllable accompanied by an ample F0 rise on that same syllable. French phoneticians like Rossi (1980) and Vaissière (2002) have described this as "un syncrétisme", a merger between lexical and supra-lexical prosody in French.

\subsection{English: word stress and intonational boundaries}

In English, however word stress is part of the identity of individual words and, as such, is fairly stable. Contrary to what happens in tone languages however, there is no pre-set melodic pattern attached to each word. Pitch movements have been described as the main correlates of word stress (the main transducer of stress for Pierrehumbert, 1980), but the exact shape of a term's melodic contour is influenced by the status of this term in the intonation unit (nucleus, head, post-nucleus, etc...) and by the associated tone in the case of a nucleus accent (fall, rise, fall rise). Many studies emphasize the impact of the 
general intonation contour over the realisation of word stress in discourse, i.e. 'accent' (see Pierrehumbert, 1980 and Gray, $2001^{3}$ for example). Pierrehumbert explained:

The relation of F0 to stress is not as direct as this. A word with a given stress pattern could have any of a number of different F0 contours depending on the intonation pattern that was being used. A given F0 pattern could be compatible with more than one conclusion about the location of stress. (Pierrehumbert, 1980: 103)

However, even though their prosodic realisations are relatively variable and contextdependent, words in discourse retain a relative accentual autonomy whose exact prosodic implementation depends on the specific intonational context expressed in a given utterance.

Considering these differences between French and English, it is not surprising that French learners of L2 English are faced with a major challenge: how can the speaker ensure the marking of lexical stress while, at the same time, using the same prosodic cues to indicate the intonation of the utterance?

The hypothesis I propose is that the prosodic realisation of certain syntacticinformational contexts is responsible for a particular difficulty in the pronunciation word stress patterns by French learners. More precisely, the correct placement of word stress will be made unstable and therefore its perception by native listeners will no longer be guaranteed. I call these contexts 'challenging' contexts.

\section{Defining the challenging contexts}

I define challenging contexts as linguistic contexts where, in L1-French, prosody is the prime marker of the syntactic and/or informational structures of the utterance. As previously posed, the prosodic cues (especially duration and fundamental frequency) are strongly constrained in French to indicate :

- Firstly, the boundaries of syntactic and/or informational units, and more particularly the right-hand boundary (or final boundary ${ }^{4}$ ). In French, what has been described as the major continuation rise ("continuation majeure") occurs at the boundary of a dependent (non-final) unit in a sentence. These ample continuation rises are perceptively very prevalent when listening to French (see figure 3 below).

In English, continuation contours have received less attention from phoneticians and there seems to be more variation in the direction and shape of the associated pitch movements with a rising, a falling-rising, and even falling contour being found (see Cruttenden, 2001 and Wells, 2006). More importantly, these boundary contours do not

\footnotetext{
${ }^{3}$ Gray (2001) also underlines the difficulty of talking of a once-and-for-all hierarchy of the acoustic cues of lexical stress or sentence stress without considering the intonation over the whole tone-unit.

${ }^{4}$ Although left-boundary marking through F0 resetting on the first syllable of the unit also exists and it is associated with microprosodic features on initial consonants for example.
} 
generally merge with the prosodic marking of lexical stress contrary to what happens in French (see Chen, 2003 and Martin, 2009 ${ }^{5}$ ).

- Prosodic cues also help to mark sentence-type (statement vs question) and maybe more so in French than in English, since in conversational French questions frequently have the syntactic form of a statement and the rising intonation is the only indication that a question is being asked.

- In French, cases where intonation alone is the marker of linguistic focus are very rare (contrary to English). Indeed, informational focus is often expressed through a combination of syntactic, lexical and intonational devices together (Martin, 2009).

\section{Experimental set-up and results}

\subsection{The corpus, the speakers and listeners}

To test my hypothesis, I proposed seven linguistic contexts whose prosodic realisation might be more or less challenging for French learners with regards to the marking of lexical stress. These contexts are numbered from one to seven and can be found in the full dialogue of Appendix A (note that the speakers were presented with the normal, unnumbered version of the script). My predictions were that challenging contexts for French learners would be: context $\mathrm{C} 1$ (end position in a non-final tone-unit or major continuation), context $\mathrm{C} 3$ (end position in a rising interrogative), and contexts $\mathrm{C} 2$ and $\mathrm{C} 4 / 5^{6}$ (respectively corresponding to cases of post-focus deaccentuation and intonational focus). On the contrary, I predicted that contexts CIT (citation form in an anchor sentence), C6 (mid-position in an intonation unit) and C7 (end position in a final declarative tone-unit) would represent less of a challenge for the prosodic marking of lexical stress by French learners of English (see Appendix B). In this paper I will focus mainly on the analysis of the contexts corresponding to unit boundaries (i.e. $\mathrm{C} 1, \mathrm{C} 3, \mathrm{C} 7$ ).

I designed a dialogue which was intended to be read by two speakers: a native English speaker and a French learner. The dialogue was written so that two trisyllabics (computer, pro'tection) would be found in all seven contexts. These two words were chosen because they are simple, common terms that learners know at this stage, and because they bear primary stress on their second syllable (thus allowing for the possibility of stress misplacement on the first or the last syllable).

\footnotetext{
${ }^{5}$ Martin (2009: 191) explains that due to this merger in French, French learners of Italian might confuse a boundary contour and word stress. («Les contours de continuation majeure, positionnés en français sur la dernière syllabe des syntagmes importants, sont réalisés dans les autres langues sur deux syllabes distinctes, la tonique par un contour plat et la finale par un contour fortement montant (à moins que la tonique ne soit en position finale). Les auditeurs francophones ne connaissant pas l'italien identifient alors ce contour comme celui de leur propre langue et attribuent faussement un accent final aux grands groupes syntaxiques. »)

${ }^{6}$ Initially, I had dissociated cases of intonational focus (C4) and contrastive intonational focus (C5). Since the phonetic implementations of these two types of focus on the test-words by native English speakers were extremely similar, I subsequently decided to gather them under one single category of intonational focus (C4/C5).
} 
The speakers were thirteen French learners of English (second-year students of English at a Parisian university, with an upper-intermediary or advanced level in English). The control group of native speakers was composed of ten speakers representing a variety of British, American, Australian and Irish speakers. Dialectal homogeneity was not an important criterion in this test, the assumption being that, beyond intra-language variation, listeners would perceive some variation as non-native (so-called 'deviations') whereas other variation would be tolerated and interpreted as native variants.

Parts of this read corpus were then used as a basis for a perception test. The testwords (protection, computer) read by the French learners and by the control group of native speakers were extracted from their context and presented in isolation to native listeners of English. The words were presented on a computer with a headset. The listeners were asked to identify the syllable they heard as the most prominent in the different test-words (the first, second or third syllable). To avoid listener fatigue, 9 subsets of stimuli were created and each was presented to four different listeners.

\subsection{The perceptual results}

Table 1 below presents the perceptual results drawn from the native-English listeners' perceived placement of lexical prominence in the two types of stimuli: perceptual judgments of the learners' productions of the two test-words appear in the top part of the graph, and in the bottom part of the graph appear the listeners' perceptual judgments of the stimuli produced by the control group of native speakers. As a control condition, listeners were also presented with native speaker productions.

On the horizontal axis, each bar corresponds to the context the word was extracted from, starting with $\mathrm{C} 1$ at the left of the horizontal axis. The different types of pattern (black, checked or dotted) convey information about the type of assessment made by the listeners. The perception of the 'correct' or predicted placement of prominence on the second syllable is not coded (e.g. comPUter). Cases when no consensus emerged from the listeners' answers, which I called cases of 'perceptive indermination', are coded with the dotted pattern in the answer bars. Answers relating to a perceived placement of prominence on the first syllable (initial stress COMputer) appear in a checked pattern and perceived prominence on the final syllable is coded in black (compuTER). 


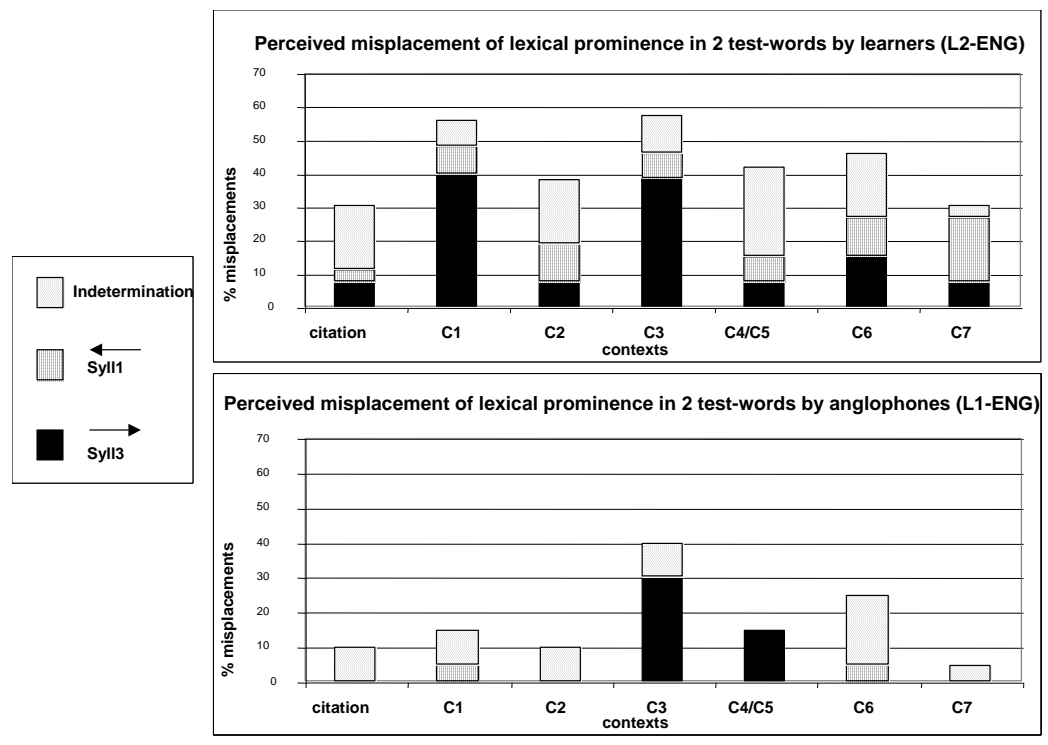

Table 1. Perception answers provided by native-English listeners on two types of stimuli: test-words produced by French-learners of English (top part) and by native-English speakers (bottom part)

The perceptual results show that:

- Perception of learners' stimuli resulted in twice as many indeterminate judgements as when they were based on native stimuli (indeterminate judgements correspond to the dotted areas).

- The answers relating to the perception of prominence on the first and on the last syllable can be grouped under one category since they reflect instances of perceived misplacement of lexical prominence. These cases of perceived misplacement are far more frequent for learners' stimuli than native speakers' stimuli (2.5 times more frequent $\left.{ }^{7}\right)$.

It might appear surprising that native productions were not exempt from judgements of misplacement, although these instances remained very exceptional. One token in particular was responsible for these unexpected judgments: ComputerC3. One reason for this might be that the question asked is not a neutral, traditional Yes/No question aiming at eliciting information. Projecting very subjective and evaluative overtones, many native speakers produced this question as an exclamative, echo-question (meaning: this can't be true!). The associated pitch rise was therefore realised as an exceptionally ample and high melodic rise. This observation also shows that the concepts of word stress (a theoretical, phonological concept) and perceived lexical prominence (a psychoacoustic, perceptive phenomenon) sometimes do not overlap completely.

${ }^{7}$ A Chi test showed that answers reflecting an incorrect placement (syllable1, syllable2 or indetermination) based on the learners' productions were signicantly different from those based on the native speakers' productions. Chi2 $(1)=24.2$ with $\mathrm{p}<0.001, \mathrm{~N} 1=182, \mathrm{~N} 2=140$. 
As regards the perception of learners' stimuli, some contexts led to more perceived misplacements than others. This was more particularly the case for contexts corresponding to tone-unit boundaries such as $\mathrm{C} 1$ (located at the major continuation at the boundary of a dependent unit in an utterance) and $\mathrm{C} 3$ (the end of a rising interrogative contour). $\mathrm{C} 1$ and $\mathrm{C} 3$ were each responsible for fifteen perceived misplacements out of twenty-six tokens. These contexts therefore favoured substantial instability in lexical prominence as perceived by native English listeners. On the other hand, other contexts favoured more stability, and in that sense, they should be considered less challenging for learners. This is particularly true of the quotation form or the end of a final (non-dependent) unit in a declarative sentence (C7).

The more challenging set of contexts were $\mathrm{C} 1, \mathrm{C} 3$ and $\mathrm{C} 6$, and the less challenging set were Citation, C2, C4/5 and C7. The difference between the perception of challenging and non challenging contexts is statistically significant ${ }^{8}$.

Parts of these results did not exactly match my initial predictions however. This can be explained by the discrepancy between the projected interpretations prompted by the dialogue and the actual realisations the learners produced. For example, contexts $\mathrm{C} 2$ and $\mathrm{C} 4 / 5$ had to be considered not relevant for the analysis of the learners' productions quite simply because the learners proved unable to produce the expected intonational focus and post-focus deaccentuation prompted by the dialogue. Contrary to native speakers who produced intonation patterns matching the projected meanings - the learners systematically produced broad focus where narrow focus was expected, therefore realising intonation patterns similar to $\mathrm{C} 7$ instead (the end of a neutral declarative sentence). Interestingly, this turned out to be the case even when intonational focusing and deaccenting were visually encouraged through the use of italics on the nuclear syllable ("It's a shame because I'm quite sure my computer already has a virus protection"). This observation shows that the central role of intonation to mark focus in English is clearly not part of the French learners' active competence at this stage.

What is more, context C6, which theoretically did not correspond to a tone-unit boundary, was often granted a separate tone-unit by learners and therefore produced with a similar pattern as $\mathrm{C} 1$ (the end boundary of a non-final tone unit). This tendency for learners to oversegment L2 speech is frequent and not language-specific, being caused by the cognitive overload of speaking in a foreign language.

Ultimately then, what seems to have been be the determining factor to account for the learners' difficulty in marking lexical stress was whether the test-word was situated at the boundary of a tone-unit or not (in the actual realisations of learners). Let's now turn to the acoustic specificities of the most challenging contexts for French learners regarding the marking of lexical prominence: contexts $\mathrm{C} 1$ and $\mathrm{C} 3$.

\footnotetext{
${ }^{8}$ A Chi test showed the set of most challenging contexts (C1, C3 and C6) received significantly more incorrect placement answers than the set of less challenging contexts $(\mathrm{C} 2, \mathrm{C} 4 / \mathrm{C} 5, \mathrm{C} 7$ and Citation). Chi2(1) $=5.3$ with $\mathrm{p}<0.05, \mathrm{~N} 1=78$ and N2 $=104$.
} 


\subsection{Acoustic analysis of contexts $\mathrm{C} 1$ and $\mathrm{C} 3$ :}

\section{a) Context 1:}

It corresponds to the continuation contour at the boundary of a dependent unit (end position in a non final tone-unit).

Eg- //The idea of a good proTECtion (C1) / is to guarantee that your computer doesn't get infected by a VIRus//

Eg- //Well, the only protection on my comPUter (C1)/is just a basic anti-VIRus software, I think// First it is interesting to observe a clear difference in the orientation of the contours produced by French learners and native English speakers. Almost all ten native English speakers produced a fall on the last two syllables of the test-word in this context (from the mid-level to the bottom level of their pitch-ranges). The slope of the falls they produced was between 1.7 and 2.9 semi-tones. The fall was sometimes followed by a very small additional rising hook as in the example below (figure 1). The solid line corresponds to the Fo curve and the dotted line corresponds to the intensity curve.

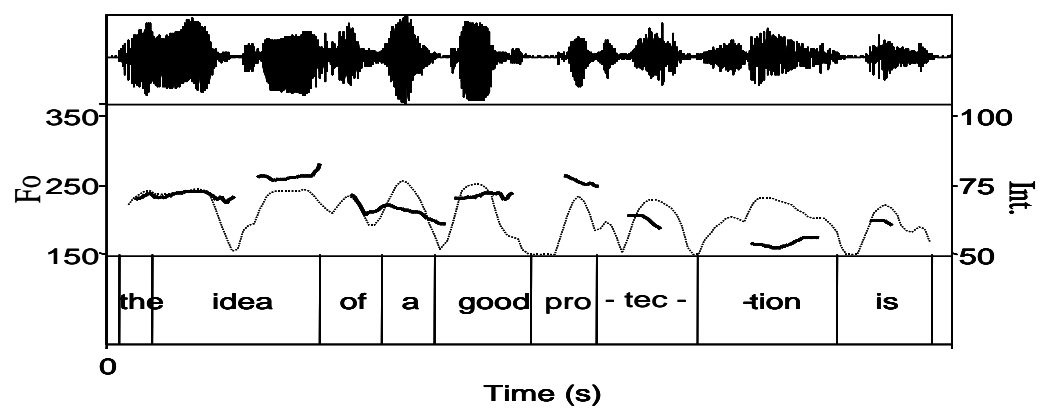

Figure 1. Native speaker, InfoN13protectionC1 (Fo range: 150-300 Hz, intensity range: 50-100 dB)

The temporal ratio of last syllable relative to the duration of the whole word (computer, protection) is similar to its ratio when produced by the same speakers in its quotation form. Therefore, there was no lengthening ${ }^{9}$ of the last syllable-tion/-ter when compared to the quotation form. A decrease in intensity between the second syllable and the last syllable of the test-words was realised by only half the native speakers and it did not seem to be as important a prosodic cue as the frequency variations for the marking lexical prominence on the test-words.

However, in the same linguistic context, most French learners produced a rise on the last two syllables. A falling contour similar to the native speakers' favoured melodic pattern was produced by only a quarter of learners for computerCl and one third for protection $C 1$. The rest of the learners realised a melodic rise between the second and the last syllable of the test-words reaching the mid-high level of their pitch ranges.

\footnotetext{
${ }^{9}$ For the control group of native speakers, the mean lengthening ratio of the last syllable (compared to the quotation form) was $-5 \%$ for computer $C 1$ and $-3 \%$ for protectionCl.
} 
Figure 2 below gives an illustration of the typical pattern realised by the French learners of the corpus. The learners lengthened the last syllable of computerCl relative to the temporal pattern observed in the quotation form but there was no substantial lenghthening for protection $C 1^{10}$.

The decrease in intensity between the second and the last syllable is not clearly realised by the group of learners.

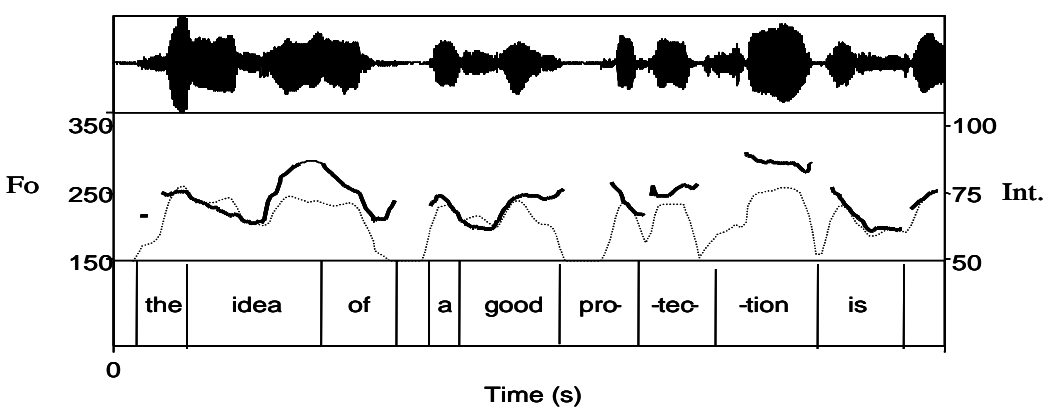

Figure 2. French learner, Info20protectionC1 (Fo range: 150-350 Hz, intensity range: $50-100 \mathrm{~dB}$ )

As previously seen, intensity might not be relevant cue to look at since it was not a systematic correlate of lexical prominence in the native speakers' productions.

It was highly revealing to compare the prosodic trends observed in the learners' productions with control data collected (for all the thirteen learners) in similar linguistic contexts in their mother tongue (French). This is particular clear in the case of 'protection' because the same lexical item was used in the French version of the dialogue.

Eg. (L1-French) // le principe d'un bon système de protectionC1/ c'est de garantir que votre ordinateur ne soit pas infecté par des virus //

Indeed, the continuation contour was realised as a systematic rise in L1 French in this C1 context. Figure 3 below shows that for the same learner as previously presented, the continuation contour is almost identical to what she produced in L2 English. The shape, alignement and pitch range of the learners' contours are very similar to what happens in her L1, which strongly supports the idea of prosodic interference of L1 French in this case.

\footnotetext{
${ }^{10}$ Their average lengthening ratio for computerCl was $9.8 \%$ and $0.5 \%$ for protectionCl.
} 


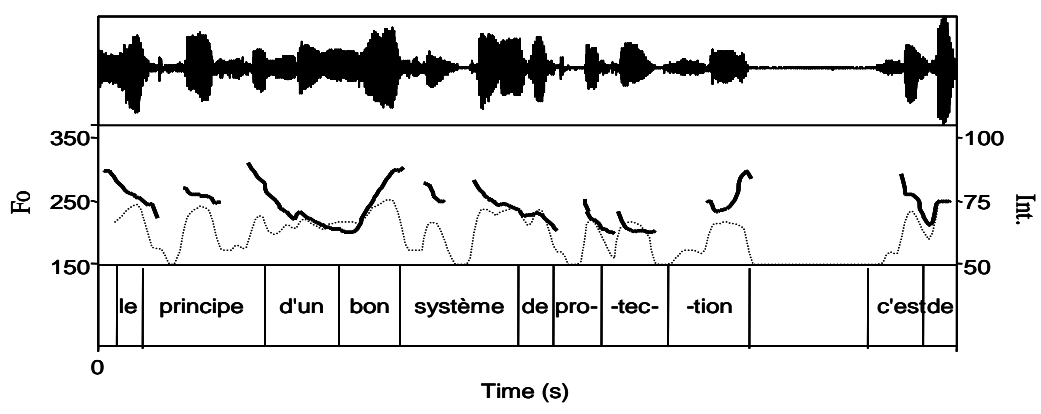

Figure 3. French speaker (L1-French), Info20protectionC1 (Fo range: 150-350 Hz, intensity range: $\mathbf{5 0 - 1 0 0 ~} \mathrm{dB}$ )

Therefore the acoustic parameters responsible for the listeners' perceived prominence on the last syllable in learners' productions are certainly related to some lenghthening of the final syllable in the test-words coupled with a deep and prominent rise starting either on the very last syllable or else stretching over the whole word. Intensity could not be considered to be a consistent cue distinguishing native speakers' and learners' productions. The analysis of the first two formants of the final target vowel /a/ did not allow me to show less centralisation in learners' productions than in native speakers' productions, due to the big variability in formant values among speakers in a same group.

The most important prosodic cues accounting for the difference between learners and native speakers' production were: the duration and pitch patterns on the last syllable. Significantly, the other most challenging context (context C3) shares most of these prosodic specificities.

\section{b) Context C3:}

It corresponds to the end of a rising interrogative.

Eg- //Is your PC equipped with any type of computer proTECtion (C3)?//

Eg- /With your comPUter (C3)?//

I will only deal with the realisation of protectionC3 here because, as previously mentioned, computer $C 3$ turned out not to be interpreted as a straightforward question and was therefore discarded from the acoustic analysis. Interesting observations can be made when looking at the oriention of Yes/No questions by the two groups of speakers (which also emerged in another production test I carried out with French learners of L2 English, Horgues, 2010).

All thirteen French learners produced a rise as the default contour on the Yes/No questions of the corpus whereas the contours realised by native English speakers were more varied. Indeed, only half the native speakers chose a simple rise, while the other half realised a fall-rise or else a simple fall. In the native speakers' productions, there seems to have been room for variation depending on the associated interpretation the speaker projected in a given utterance. When comparing rising contours by learners and English speakers, the alignment of the final rise also differs between the two groups. Indeed, the start of the rise is in strict alignment with the syllable carrying primary lexical stress in native productions, the rise being initiated only on the stressed syllable 
which is anchored at the bottom level. In the learners' productions, however, the rise is not strictly aligned with the theoretically stressed syllable: it rather stretches over the whole word (compare figure 4 and figure 5 below).

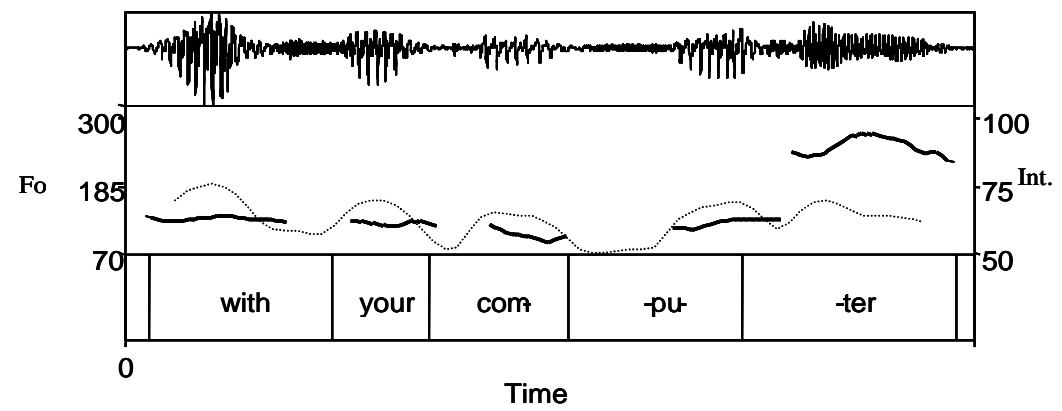

Figure 4. Native speaker, InfoN12computer (Fo range: 70-300 Hz, intensity range: $\mathbf{5 0 - 1 0 0 ~} \mathrm{dB}$ )

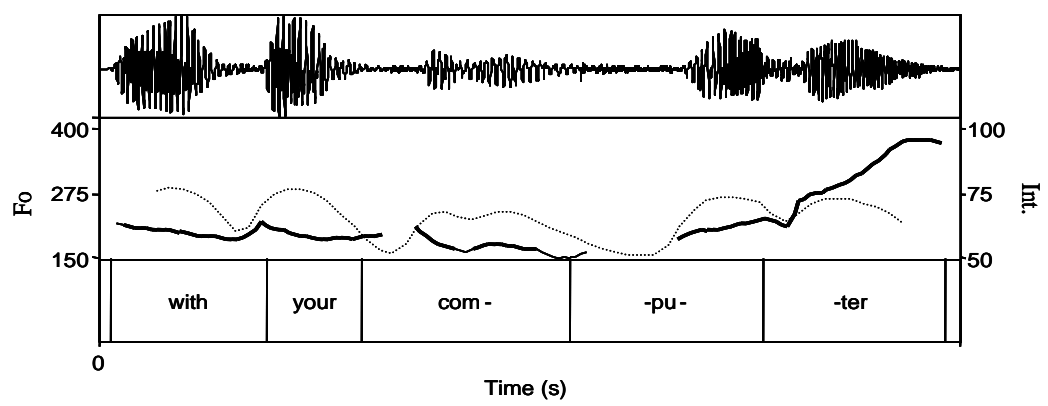

Figure 5. French learner, Info26computerC3 (Fo range: 70-400 Hz, intensity range: $50-100 \mathrm{~dB}$ )

What contexts $\mathrm{C} 1$ and $\mathrm{C} 3$ have in common is the way learners realise them: through a lengthening of the last syllable, associated with a pitch rise and an increase in intensity. Interestingly, another type of tone-unit boundary ( $\mathrm{C} 7$, the end of a declarative statement) did not represent the same level of difficulty, due to the fact that the associated pitch contour is falling and that there is a natural decrease of intensity at the end of a falling declarative statement.

\section{Conclusions and pedagogical perspectives}

The results of the perception test investigating perceived lexical prominence confirmed that most prosodic contexts that were predicted to be challenging for French learners of L2 English indeed caused substantial instability in the perception of lexical prominence by native English listeners. 
This tends to show that, at this level of competence, even though most learners already have a phonological representation of a word's stress pattern, its phonetic implementation should not be taken for granted. Indeed, some particular prosodic contexts make the implementation quite unstable although the pronunciation of the citation form is correct. We cannot simply blame the so-called 'stress deafness' of French learners of English. I think this would be too simplistic as it would suggest their complete inability to hear and produce word stress in English, which is not the case. What rather appeared in this experiment is that their ability to mark and maintain word stress prosodically was endangered or challenged in some particular contexts more than others. The prosodic constraints imposed at the supra-lexical (intonational) level seem to have an impact on the misplacement of lexical stress. French learners find it particularly difficult to realise the necessary dissociation of prosodic cues required to mark both lexical prominence and intonational patterns across the whole utterance.

The incorrect realisation of lexical stress patterns by learners is not inconsequential since it is widely acknowledged that it can cause a loss of intelligibility in L2 speech. Revealingly, most cases of misplacement in this experiment resulted in a stress-shift towards the last syllable of the test words (therefore: protecTION, compuTER). As Field (2005) has shown, right-hand stress-shifts have a particular negative impact on the segmentation of continuous speech by native English listeners (possibly more so than left-hand shifts). Intelligibility and lexical access are therefore seriously impaired.

Supra-lexical prosody not only imposes constraints on the realisation of stress patterns by learners but it can also represent a learning challenge for the pronunciation or the perception of certain phonemes or of intonational focus. For instance, Gray (2001) has shown that a rising contour or a falling-rising contour in English represented a challenge for French learners' perception of minimal phonemic pairs (bead/bid), lexical stress patterns or sentence stress patterns.

Once again, these results should encourage EFL teachers to depart from a form of teaching based on presenting word stress patterns in isolation. Theoretical knowledge about a word's stress pattern and the correct pronunciation of its quotation form is no guarantee that learners will be able to realise the expected lexical prominence when that same word is used in different discourse contexts. One suggestion would be to take more into account the impact of intonational constraints in the teaching of English phonology and phonetics. When teaching French learners the perception and production of English stress patterns for example, we might envisage a progressive exposition starting with less challenging prosodic contexts before moving to more challenging ones.

\section{References}

Bolinger, D. L. 1978. Intonation Across Languages, Universals of Human Language, Greenberg, J.H. (ed.) California, Stanford University Press, vol.2, 471-524.

Hirst, D. J. and Di Cristo A. 1998. Intonation Systems: a Survey of Twenty Languages, Cambridge: Cambridge University Press.

Chen, A. 2003. Language Dependence in Continuation Intonation, Proceedings of the $15^{\text {th }}$ International Congress of Phonetic Sciences, Barcelona: UAB, 1069-1072.

Cruttenden, A. 1997. Intonation, Cambridge : Cambridge University Press. 
Dupoux, E. and S. Peperkamp, S. 2002. A typology of Stress 'Deafness', in C. Gussenhoven and N. Warner (eds.), Laboratory Phonology 7, Berlin: Mouton de Gruyter, 203-240.

Dupoux, E. ; Pallier, C. ; Mehler, J. ; Sebastian, N. (2003b) A Destressing 'Deafness' in French ?, Journal of Memory and Language, 36, p. 406-421.

Delattre, P. 1965. Comparing the Phonetic Features of English, French, German and Spanish: an Interim Report, Heidelberg : Julius Groos.

Field, J. 2005. Intelligibility and the Listener: the Role of Lexical Stress, TESOL Quarterly, 39(3), 399-423.

Fónagy, I. 1980. L'accent en français: accent probabilitaire, in Fónagy, I. and P. Léon. (eds.), L'accent en français contemporain, Studia Phonetica, 15, 123-227.

Frost, D. 2011. Stress-Cues to Relative Prominence in English and French: a Perceptual Study, Journal of the International Phonetic Association (41/1)

Garde, P. 1968. L'accent, Paris: Presses Universitaires de France.

Grover, C., Jamieson D. and M. Dobrovolski. 1987. Intonation in English, French and German: Perception and Production, Language and Speech, 30(3), 277-295.

Gray, M. 2001. Place et rôle de l'intonation dans l'apprentissage de l'anglais, unpublished $\mathrm{PhD}$ dissertation, Université Paris 12.

Hewings, M. 1998. Intonation Choices in the English Intonation of Non-Native Speakers, an Exploratory Study, in Sánchez-Macarro, A ; Carter, R. (eds.), Linguistic Choice Across Genres: Variation in Spoken and Written English, Amsterdam : John Benjamins. p 317-336.

Horgues, C. 2010. Prosodie de l'accent français et perception par des auditeurs anglophones, unpublished $\mathrm{PhD}$ dissertation, Université Paris Diderot-Paris 7.

Konopczynski, G. 1991. Le Langage émergent: Aspects Vocaux et Mélodiques, Hamburg: Ed. Buske Verlag.

Kuhl, P. K. ; Iverson, P. 1995. Linguistic Experience and the 'Perceptual Magnet Effect', in Strange, Speech Perception and Linguistic Experience, Issues in Cross-language Research, p. 121-154.

Martin, P. 2009. Intonation du français, Paris: Armand Colin.

Pierrehumbert, J. 1980. The Phonology and Phonetics of English Intonation, PhD Thesis, MIT, Indiana University Linguistics Club

Rossi, M. 1980. Le français, langue sans accent?, in Fónagy, I. and P. Léon (eds.), L'accent en français contemporain, Studia phonetica, 15, Ottawa: Didier, 13-52.

Tahta, S. ; Wood, M. ; Loewenthal, K. 1981. "Foreign Accents: Factors Relating to Transfer of Accent from the First Language to a Second Language", Language and Speech, 24, p. 265-272.

Troubetzkoy, N. S. 1939. Grundzügue der Phonologie, Travaux du Cercle Linguistique de Prague, 7; French translation by Cantineau, J.: Principes de phonologie, Paris: Klincksieck, 1949.

Vaissière, J. 2002. Cross-linguistic Prosodic Transcription: French versus English, Problemy I metody eksperimental'no-foneticheskih issleddovanij, St;-Petersburg: StPetersburg State University, 147-164.

Wells, J. 2006. English Intonation: an Introduction, London: Longman.

Wenk, B. J. and F. Wioland. 1982. Is French Really Syllable-Timed?, Journal of Phonetics, 10(2), 193-216. 


\section{Appendix A}

Full script of the dialogue read and enacted by a native English speaker and a French learner of L2 English:

[on the phone, a customer $(C)$ and a hotline operator $(O p)$ ]

(C)-Is this the Computer (C6) Protection Assistance Service?

(Op)-Yes Madam/Sir, what can I do for you?

(C)-Oh Hello! I'm calling to report a serious problem with my computer (C7).

You see, a few years ago, my brother Henry gave me his old computer (C1) and I've been using it at home. It's a PC.

I also have a brand new one at the office and that one works perfectly well.

(Op) -OK....Well I might be able to help you if you actually tell me what is wrong with your computer (C2). By the way, do you mind if our service records our conversation? This is for....

(C)-Um...well, collecting and recording details about your customers is one thing, but going as far as recording a conversation is a little surprising...

In fact, it is not particularly pleasant, but if you say you're doing this to improve your service...I suppose I don't mind...

(Op) -Thank you, Madam/Sir. We'll try to do our best to help. Let me start off with a few questions: Is your PC equipped with any type of computer protection $(\mathbf{C 3})$ ?

(C)- any computer what?

(Op) - computer protection $(\mathbf{C 4 / C 5 )}$. You know, the best way to make sure that your PC is safe from viruses is to install a reliable system of protection $(\mathbf{C} 7)$.

Does your PC have one?

(C)-Well, the only protection (C6) on my computer (C1) is just a basic anti-virus software, I think. I can't remember the name now.

The thing is, it makes the machine really slow and after all...do I really need this stuff?

$(\mathrm{Op})$ - Well, as I said the idea of a good protection (C1) is to guarantee that your computer doesn't get infected by a virus.

You see, a virus attack could seriously damage it.

(C)-Um....I suppose it has its advantages....but...do you mean I need to buy a new one? It's a shame because I'm quite sure my computer already has a virus protection (C2).

(Op) - We'll see about that. First, could you give me the details of your computer's (C6) brand and serial number please?

(C)-Um...well... you know, it's now become rather difficult to have a conversation.

(Op) -With your computer $(\mathbf{C 3})$ ?

(C)-Of course not!!! You really don't get it, do you? Do you really think I'm stupid enough to try and have a conversation with a machine!

I wasn't talking about my computer (C4/C5)... I'm talking about Henry, my brother!!

(Op) - So, you're not on particularly good terms with your brother anymore, from what I understand?

(C)- No.....and I remember quite clearly the conversation that we had about this damn computer. I haven't spoken to him since.

(Op) -I'm sorry about that. What I can say is that it's definitely not always easy to have a calm conversation about computers....

(C)- No, you're probably right...

(Op)- Especially because for some reason, people tend to get completely worked up about technical problems! 


\section{Appendix B}

\section{More challenging contexts?}

* C1- End of a dependent (non-final) tone-unit in the utterance

Eg- //The idea of a good proTECtion (C1) / is to guarantee that your computer doesn't get infected by a VIRus//

Eg-//Well, the only protection on my comPUter (C1)/ is just a basic anti-VIRus software, I think//

* C2- Deaccentuated post-nuclear position (tail of the tone-unit in the British theory)

Eg- //It's a shame because i'm quite sure my computer already HAS a virus protection (C2)//

Eg- //Ok...Well $i$ might be able to help you/ if you actually tell me what is WRONG with your computer $(\mathbf{C 2}) / /$

* C3- Final position of a rising interrogative contour

Eg- //I your PC equipped with any type of computer proTECtion (C3) ?//

Eg- //With your comPUter (C3)?//

* C4- Intonational focus or C5- Intonational contrastive focus

Eg- //any computer WHAT?// (Op) - //Computer proTECtion (C4/5) //

Eg- //I wasn't talking about my comPUter (C4/C5) /I'm talking about HENry/ my BROther//

$>\quad$ Less challenging contexts?

* CIT-Quotation/citation form (in anchor sentence)

Eg- // That's a proTECtion, she said // or //That's a comPUter, she said//

* C6- Mid-position in a tone-unit :

$\mathrm{Eg}$ ://Well, the only protection (C6) on my comPUter/ is just a basic anti-VIRus software//

$\mathrm{Eg}$ : //FIRST,/ could you give me the details of your computer's (C6) BRAND/ and SERial number, please?//

* C7- Final position in last tone-unit of a declarative statement

$\mathrm{Eg}$ : //You KNOW/ the best way to make sure that your pc is safe from VIRuses/ is to install a reliable system of proTECtion $(\mathbf{C 7}) / /$

$\mathrm{Eg}$ : //Oh helLO/ I'm calling to report a serious problem with my comPUter $(\mathbf{C} 7) / /$

Transcription conventions:

Test-words are underlined

Bold type: prominence on the test-words' syllables.

Capital letters: nucleus (tonic syllable) in the tone-unit.

Test-words are underlined 